\section{Professores pensando sobre neurociência e educação}

\section{Teachers thinking about neuroscience and education}

Claudia Lopes da Silva é doutora em Educação pela Faculdade de Educação da Universidade de São Paulo (FEUSP), psicóloga escolar da Secretaria de Educação de São Bernardo do Campo (SP) e professora universitária do Instituto Superior de Educação Vera Cruz e Unimes Virtual.

Contato: psi.clau@gmail.com

\section{Resumo}

A educação tem demonstrado entusiasmo em relação às descobertas da neurociência, provavelmente com base na expectativa de aplicá-las à escola em busca de uma melhoria no processo de ensino e aprendizagem. Essa parceria, no entanto, precisa ser vista com cautela, pois ainda é distante o espaço entre o laboratório e a sala de aula. Em tal cenário, são bem-vindas as iniciativas de aproximação que privilegiem uma postura reflexiva, evitando cair na tentação de buscar respostas fáceis para as complexidades enfrentadas pela escola atual. 0 presente artigo relata uma experiência nesse sentido, discutindo a visão de professoras participantes de um curso de extensão sobre a temática, realizado em dez encontros, sob o recorte teórico da psicologia histórico-cultural de Vigotski'. Trata-se, portanto, de um olhar para as descobertas da neurociência a partir da perspectiva da educação, e espera-se que, a partir deste estudo, possa-se contribuir para iluminar tal relação de uma forma crítica no que se refere à possibilidade de interlocução. Palavras-chave: neurociência e educação; psicologia histórico-cultural.
1. Neste trabalho, emprega-se a grafia Vigotski, por ser a utilizada nas traduções mais recentes da obra do autor. Outras publicações, contudo, utilizam diferentes grafias (como Vygotsky), que, ao serem aqui referidas, serão preservadas em sua apresentação original, o que impedirá a padronização do nome do autor nas citações feitas neste trabalho. Para maiores detalhes sobre esta questão, sugere-se a consulta de DUARTE, N. Vigotski e o aprender a aprender. 2 ed. Campinas: Autores Associados, 2001. Nota de rodapé p. 2-3. (SILVA, 2006) 


\begin{abstract}
Education has shown enthusiasm for the discoveries of neuroscience, probably based on the expectation of applying them to school in search of an improvement in the learning process. This partnership, however, must be viewed with caution, because the distance is still far from the laboratory and the classroom. In this field, are welcome initiatives that favor an approach reflective stance, avoiding the temptation of looking for easy answers to the complexities faced by the current school. This paper reports an experience in this direction, discussing the vision of teachers who participate in an extension course on the subject, held ten meetings, under the theoretical framework of cultural-historical psychology of Vigotski. It is therefore a look from education to the findings of Neuroscience, and it is expected that, from this reflection, can contribute to this relationship to illuminate a critical as regards the possibility to interchange. Keywords: neuroscience and education; historic-cultural psychology.
\end{abstract}

Este artigo tem como objetivo realizar um relato de experiência a partir de um curso de extensão oferecido para educadores sobre a temática neurociência e educação. A proposta do curso surgiu da pesquisa de doutorado da autora, que enfoca o papel do cérebro na psicologia histórico-cultural de Vigotski; as raízes de tal estudo se estendem à experiência profissional como psicóloga escolar em uma rede pública de ensino fundamental I. Nesse trabalho como psicóloga escolar, dedicado principalmente às questões surgidas em decorrência da inclusão de alunos com diferenças significativas ou deficiências, é comum a defesa de educadores quanto à necessidade de diagnósticos médicos, na expectativa de, por meio deles, orientarem seu trabalho pedagógico.

Em tal cenário, o neurologista acaba tendo uma voz de destaque, sendo frequentes laudos ou mesmo prescrições de medicação cuidadosamente anexadas ao prontuário escolar dos alunos. As perguntas motivadoras, que se desdobraram até a pesquisa de doutorado, foram: por que se busca no cérebro do aluno, de forma individual, a explicação para suas supostas dificuldades? De acordo com o que se sabe hoje - por exemplo, sobre a capacidade do cérebro de remodelar-se continuamente (a chamada plasticidade cerebral) -, não estaria nesse mesmo cérebro a possibilidade de superar tais dificuldades? 
Atualmente, observa-se um grande interesse por parte de educadores em temas relacionados ao cérebro. Em publicações especializadas para professores, é frequente a publicação de artigos que têm o cérebro como assunto, discutindo as possíveis implicações das descobertas da neurociência para o processo de ensino-aprendizagem. Veja-se, por exemplo, os títulos e resumos de algumas matérias recentemente veiculadas na revista Nova Escola, publicação voltada para professores:

\footnotetext{
Estímulo nos três primeiros anos é fundamental - Para a neurocientista Lisa Freund, que participou do Seminário Internacional de Educação Infantil em Brasília, ler para as crianças é um dos principais combustíveis do desenvolvimento cerebral. ${ }^{2}$

Música para aprender e se divertir - A iniciação musical na Educação Infantil e nas séries iniciais do Fundamental estimula áreas do cérebro da criança que vão beneficiar o desenvolvimento de outras linguagens. ${ }^{3}$

A hora certa de aprender - Especialistas recomendam que as escolas revejam os turnos de aula para ajustá-los ao relógio biológico da garotada. ${ }^{4}$
}

Além dessa revista, mais especificamente direcionada ao docente, também na mídia dirigida ao grande público são frequentes reportagens sobre o funcionamento do cérebro, bem como sobre medicamentos e alimentos relacionados a uma suposta melhoria da performance cognitiva e à prevenção de doenças degenerativas relacionadas ao envelhecimento, para citar alguns exemplos.

Mas o que há de verdadeiro nessa relação? Será que esse entusiasmo se fundamenta em evidências concretas? De acordo com Goswami (2006), os educadores têm manifestado ansiedade em incorporar na sala de aula as descobertas neurocientíficas, o que alimenta a propagação de supostos métodos de ensino baseados na neurociência, mas cuja fundamentação científica é discutível. Tal prática, bastante comum em países como a Inglaterra e os Estados Unidos, ainda não é tão expressiva no Brasil, apesar de dar mostras de crescimento. Como exemplos desses supostos métodos embasados na neurociência, Goswami (2006) cita um curso para professores que os orientava a identificar os alunos como tendo dominância do lado esquerdo ou do lado direito do cérebro, com base na suposição de que cada pessoa teria um tipo de processamento dominante, suposição provavelmente fundamentada numa interpretação literal da especialização hemisférica da atividade cerebral. Com isso, os professores são aconselhados a equilibrar as atividades da sala de aula, incorporando características dos dois lados do cérebro e
2. Disponível em: <http://revistaescola.abril.com.br/educacao-infantil/0-a-3-anos/ estimulo-tres-primeiros-anos-fundamental-419560.shtml>. Acesso em: 15 jan. 2012.

3. Disponível em: <http://revistaescola.abril.com.br/educacao-infantil/4-a-6-anos/ musica-aprender-se-divertir-422851.shtml>. Acesso em: 15 jan. 2012.

4. Disponível em: <http://revistaescola.abril.com.br/ciencias/fundamentos/hora-certa- aprender-467203.shtml>. Acesso em: 15 jan. 2012. 
evitando um desencontro entre o suposto referencial do aluno e a aprendizagem. Outro curso os instrui a identificar os alunos como visuais, auditivos ou cinestésicos por meio de etiquetas com as letras V, A ou C, a fim de orientar o trabalho com as turmas.

Ainda mais peculiar é o pacote comercial intitulado Brain Gym (Ginástica Cerebral), que orienta a realização de movimentos corporais a partir dos quais as áreas do cérebro seriam integradas, resultando em uma melhor aprendizagem, de forma que os estudantes acessem áreas do cérebro que antes estavam fora do seu alcance. Nesse sentido, os alunos são orientados a acionar botões do cérebro localizados sob suas costelas para ativar o sistema visual na leitura e escrita.

Por mais estranho que possa parecer, esse tipo de aplicação de conhecimentos científicos da neurociência na sala de aula encontra grande aceitação por parte dos educadores. Para Geake (2008), tal aceitação acrítica mereceria, por si só, um estudo. 0 autor lança como hipóteses explicativas para isso a pressão política para a obtenção de resultados rápidos na educação e um melhor desempenho nas avaliações do sistema a fim de alcançar uma melhor posição no ranking de escolas, o que acaba descaracterizando o trabalho escolar individualizado, uma vez que, por trás dessa busca, existe a expectativa de encontrar uma solução padronizada para toda espécie de problemas.

Graças a esse fascínio exercido pelos assuntos relacionados à neurociência, muitas vezes a capacidade crítica do professor fica nublada sob tais rótulos. Nesse sentido, é interessante o relato de Goswami (2008) sobre os achados de Weisberg et al. ao submeterem a dois grupos distintos explicações superficiais para fenômenos psicológicos, sendo que, para um dos grupos, as explicações eram acompanhadas por dados neurocientíficos irrelevantes para o que estava sendo relatado. Apesar disso, o grupo que teve acesso aos dados neurocientíficos classificou as explicações como mais adequadas, o que levou os pesquisadores a concluírem que as explicações apoiadas na neurociência são sedutoras e conduzem com mais facilidade à suspensão do juízo crítico sobre os fatos apresentados.

Foi a partir desse tipo de evidência que se propôs o conceito de neuromito (OECD, 2007). 0 neuromito surge como resultado do próprio desenvolvimento da atividade científica, construída por meio de tentativas e erros em que uma nova teoria contradiz ou completa a anterior, e assim sucessivamente. No entanto, uma hipótese científica pode deixar traços após ser refutada, ainda mais 
se se tornou popular ou se de alguma forma captura a imaginação do público ao ser divulgada pelos meios de comunicação (OECD, 2007). A própria ciência tem dificuldade em derrubar um neuromito. Isso, aliado ao fato de esse tipo de ideia mais digerível ser bem acolhido pela mídia, evidencia a dificuldade em esclarecer tal crença, pois sua permanência não se dá por razões científicas, e sim por ter adquirido entusiastas em torno de si (Geake, 2008). Alguns exemplos de neuromitos são: "Nós só usamos $10 \%$ da nossa capacidade cerebral"; "0 cérebro do homem é diferente do da mulher"; "Tudo o que é importante no desenvolvimento cerebral acontece até os três anos, portanto não há tempo a perder"; "Eu funciono mais com o cérebro-direito, ele é mais cérebro-esquerdo"; "Todos têm um canal prioritário: visual, auditivo ou cinestésico"; "A neurociência comprovou a existência das múltiplas inteligências", entre outros (Geake, 2008; OECD, 2007).

Acrescente-se a esse cenário o interesse e a orientação teórica da autora pela psicologia histórico-cultural. A pesquisa sobre a obra de Vigotski mostra que o psicólogo bielorrusso teorizou acerca do papel do cérebro no desenvolvimento humano e de como isso se articula com o contexto social e cultural onde o indivíduo é criado. Na obra desse autor, há vários assuntos provocantes e que mereceriam ser discutidos por educadores, podendo gerar um olhar mais atento à diversidade humana e às inúmeras possibilidades de desenvolvimento que os seres humanos podem ter caso sejam adequadamente estimulados.

A motivação para o referido curso nasceu dessa maneira; a proposta, porém, não estava delimitada de forma absoluta. Antes, havia um fio condutor de assuntos que seriam interessantes de serem discutidos com um grupo de educadores, no sentido de esclarecer uma questão que vem provocando os pesquisadores da área de neurociência e educação: afinal, como essas pesquisas podem refletir-se na escola?

Willingham (2009) observa que os campos epistemológicos da neurociência e da educação são pouco compreensíveis mutuamente. Além disso, de que modo os dados de natureza química ou elétrica da pesquisa neurocientífica podem ser traduzidos em termos de dados comportamentais, como é próprio das pesquisas educacionais? Por exemplo, se em uma pesquisa de laboratório verifica-se que o sulco intraparietal contribui para o sentido de número, de que modo isso pode contribuir para a educação? De acordo com Willingham (2009), esse tipo de dado só faria sentido em face de uma teoria comportamental consistente, o que ainda não está estabelecido. 
Bruer (1997) escreveu um artigo - bem conhecido pelos pesquisadores de neurociência e educação - em que afirma que a ponte que deveria unir os dois campos é longa demais, necessitando, por isso, de disciplinas mediadoras como a psicologia cognitiva. Esse tipo de ideia, no entanto, geralmente é desconhecido dos educadores que se interessam pelos achados da neurociência. A proposta de fazer um curso apresentando reflexões dessa natureza incorreria certamente na possibilidade de decepcionar os participantes. Ainda assim, com base na única certeza de que o campo de interlocução entre neurociência e educação não poderia fundamentar-se em mentiras e de que talvez a possibilidade mais clara de interlocução estivesse numa apropriação mais consistente desse tipo de conhecimento pelos educadores, decidiu-se levar o projeto do curso adiante.

0 projeto de conteúdo do curso foi composto por uma introdução a alguns conceitos básicos sobre cérebro e neurociência, passando pela discussão das bases filosóficas envolvidas - por exemplo, a temática do sujeito cerebral apontada por Ortega e Vidal (2007) e algumas provocações dos filósofos da mente. Após essa etapa, a proposta era conhecer um pouco mais sobre o cérebro em termos das descobertas atuais, como a neuroplasticidade e a neurogênese. Em seguida, a discussão seria sobre os neuromitos, abordando as falsas concepções sobre neurociência e educação. Após essa visão geral, a ideia era aprofundar-se mais na psicologia histórico-cultural, explorando a concepção de Vigotski sobre o cérebro e, a partir disso, pensar conceitos como memória, atenção e percepção, bem como emoção e cognição como uma unidade dialética. Na sequência, propunha-se discutir algumas possíveis articulações entre a psicologia histórico-cultural e a neurociência, por meio de noções como zona de desenvolvimento proximal, funções psicológicas superiores, desenvolvimento cultural, instrumentos e defectologia. Depois, visava-se aprofundar em questões da escola, como educação inclusiva e neurociência, bem como autismo e cérebro social. Também se propunha discutir a questão da medicalização da educação, especificamente os casos de TDAH e dislexia, e o conceito de educação baseada em evidências.

Considerando-se tais objetivos, percebe-se que o projeto era bastante ambicioso, ainda mais tendo em vista que o curso compunha-se de dez encontros de três horas cada. A concepção norteadora, porém, era justamente a apresentação de tais pontos polêmicos e a discussão sobre eles. 0 propósito era saber o que os professores pensam a respeito dos assuntos levantados, e não esgotar a discussão de temas tão abrangentes como os descritos. 
A metodologia do curso precisaria, por sua própria definição, incluir a possibilidade de refletir sobre os assuntos tratados de uma forma mais sistemática, além das aulas dialogadas. Dessa forma, propôs-se aos alunos que, ao final de cada aula, respondessem de forma breve a duas questões: 1) Qual é minha opinião sobre o que discutimos hoje?; 2) Quais são as possíveis relações que eu posso estabelecer entre o que discutimos e a escola? As repostas alimentariam um blog do curso, onde as alunas também poderiam publicar. Além disso, o curso disponibilizava em um site o material didático utilizado, como as apresentações das aulas e links para vídeos.

Todas as aulas se iniciavam com a leitura e a discussão de uma notícia sobre neurociência, a fim de reforçar a atualidade das discussões e a velocidade das mudanças no campo de pesquisa. A própria escrita deste artigo, por fim, foi vislumbrada com as alunas como uma forma de registrar o conhecimento ali produzido, justamente por se tratar de uma área nova de pesquisa. Assim, realiza-se aqui uma síntese comentada das respostas que foram sendo fornecidas pelas alunas às perguntas reflexivas propostas; a partir dessa síntese, tecem-se algumas considerações para a pesquisa na área e para a avaliação do curso, visando a sua continuidade.

0 grupo constituiu-se de dezenove pessoas envolvidas de forma mais ou menos direta com educação, ou seja, além de professores, também havia coordenadores e assessores educacionais. A grande maioria dos alunos trabalhava em instituições particulares, sendo que apenas uma aluna trabalhava em escola pública e outra em um programa socioeducativo vinculado à Prefeitura de São Paulo. Ao final do curso, o grupo havia se reduzido a treze alunas, porque seis desistiram ou não chegaram a ser frequentes na maior parte das aulas.

Logo ao se apresentarem, muitas pessoas relataram que estavam ali por acharem o tema interessante e por quererem aprender mais sobre ele. Outras buscavam novos caminhos para o trabalho em sala de aula, dada a diversidade dos alunos com que trabalhavam. A questão do alunado com deficiência também apareceu de forma específica nas falas de cerca de metade das alunas, sendo feitas referências específicas a Vigotski e à psicologia histórico-cultural.

A partir da exposição da proposta, logo na primeira aula despontou um tema que seria recorrente no curso: o respeito às diferenças individuais de cada aluno e à sua forma de aprender. 
Parece que o grande dilema que se traçava era: como seria possível contemplar a necessidade de um olhar individual para o aluno em uma organização escolar estruturada como coletividade e muitas vezes massificante? Essa questão pôde ser discutida em mais de uma ocasião, e as alunas apresentaram contribuições importantes em resposta às provocações da professora. As respostas iam no sentido de que todos os alunos podem aprender, e a permeabilidade do cérebro às novas aprendizagens durante toda a vida parecia reforçar tal posicionamento. Algumas alunas também expressaram sua frustração diante dessa uniformização, no sentido de que dispunham de poucos recursos para investirem numa aprendizagem diferenciada, devido às pressões institucionais da escola. Outras apontaram a questão da dicotomia entre o cognitivo e o afetivo, dicotomia esta alimentada pela escola tradicional, de maneira que se considerava que as manifestações afetivas dos alunos não passavam de obstáculos ao processo educativo, havendo interesse em saber mais sobre as pesquisas neurocientíficas que têm afirmado o contrário.

A ideia de uma busca de eficácia também esteve presente nas falas iniciais das alunas. 0 desejo parecia ser de uma busca da resposta mais adequada, de uma maior eficácia com base no conhecimento do cérebro. Desde o primeiro dia, procurou-se de deixar claro que a proposta do curso não era fornecer esse tipo de resposta, e sim apresentar o tipo de questões que a pesquisa vinha produzindo. As respostas para temas referentes à educação, portanto, não poderiam ser dadas por neurocientistas, assim como não podem ser dadas por psicólogos ou médicos. Elas devem ser produzidas pela reflexão do educador. Isso certamente decepcionou algumas alunas, mas a maioria delas pareceu aceitar a proposta, que terminou sendo bem avaliada.

O tema da responsabilização do educador pela aprendizagem do aluno também logo foi levantado. Parecia promissora a possibilidade de discutir o perigo envolvido no recurso à neurociência para rotular supostas deficiências dos alunos, o que também foi discutido em muitas oportunidades e revelouse um tema frutífero. A ideia expressa era de que a ciência poderia integrar-se às práticas do educador para entender o desenvolvimento humano, ainda que não estivesse claro como isso poderia ser feito.

A discussão sobre os pressupostos filosóficos relativos ao cérebro foi bastante produtiva e parece ter desestabilizado o grupo, no bom sentido. Questões como a existência ou não do 
livre-arbítrio, ou o dilema do materialismo versus idealismo, parecem ter inquietado o grupo, que foi profícuo na produção escrita. Algumas temáticas interessantes despontaram, como a responsabilidade sobre a construção da consciência dos alunos. A seguir, alguns exemplos:

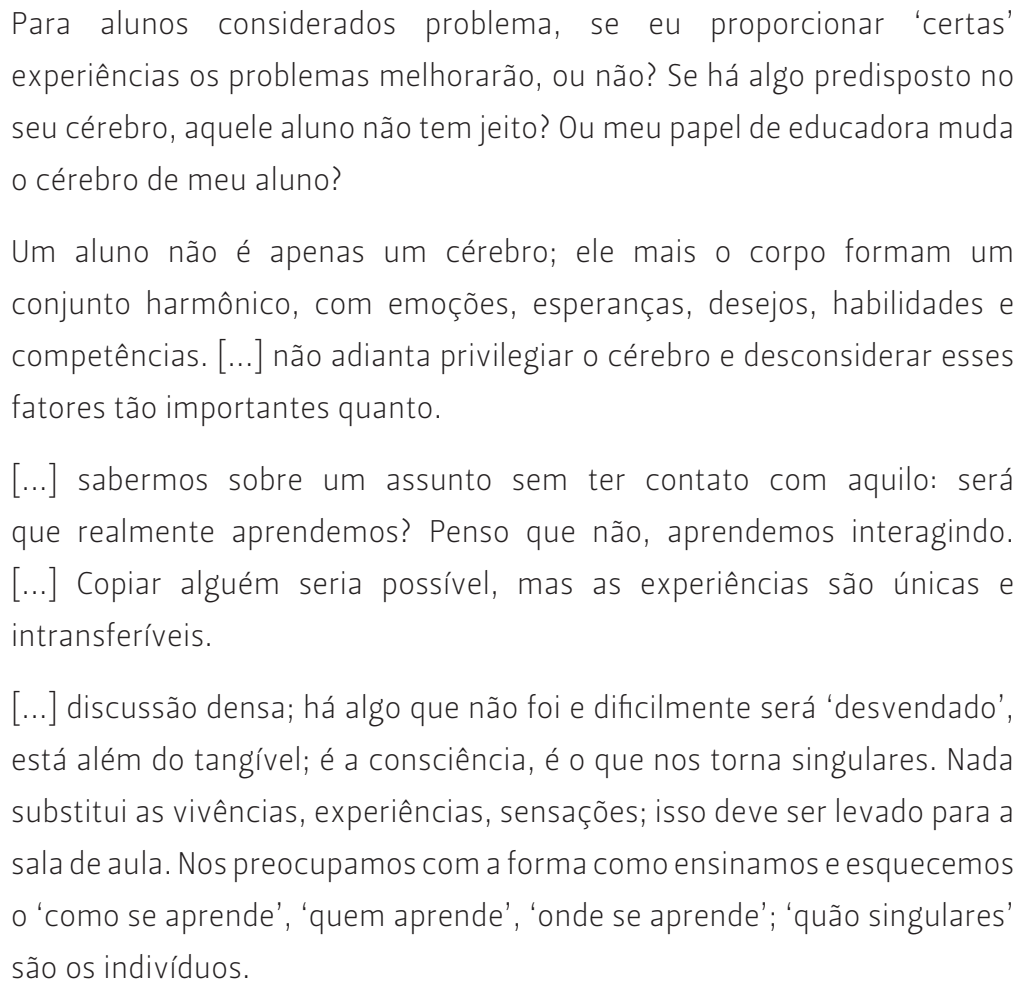

Para outras alunas, no entanto, era difícil ver a relação entre o que se estava discutindo e a escola:

são discussões difíceis de ser concluídas, pois em sua maioria são fictícias.

[...] discussão não foi esclarecedora, deixou mais confusa. Discutimos e não concluímos nada; tema proposto não era discutível. Não consigo estabelecer relação entre o que discutimos e a escola.

É interessante notar que, o tempo todo, as questões filosóficas permeiam a relação neurociência e educação; quando se sai da superfície da discussão, invariavelmente se depara com questões que não têm resposta, num cenário bem diferente das digeríveis certezas oferecidas pelos neuromitos.

Em outras falas:

[... o que discutimos tem tudo a ver com a escola, acesso do povo a 'laudo cerebral' é desempenho escolar dos filhos, relação com desempenho 'bom' no 'mercado'. A escola deveria se pautar pela neurodiversidade como questionadora do mercado. Inclusão mostra que não existe super cérebro; há cérebros e pronto. 


\begin{abstract}
Após debate 'racional', como enxergar minhas crianças na escola? Pequenos cérebros cheios de experiências ou seres humanos bastante emotivos e sensoriais? Como equilibrar esses dois polos respeitando individualidade do aluno? Relevante, despertou questões sobre ciência, ética, moral, sensações e sentimentos; vivência e experiências são fatores importantes.
\end{abstract}

0 objetivo da aula, portanto, foi atingido.

A aula sobre as potencialidades do cérebro foi mais agradável para as alunas, que se mostraram bastante receptivas ao tema. 0 conhecimento do professor a esse respeito foi apontado como importante para que o aluno possa ser visto como "sujeito em constante aprendizagem e desenvolvimento"; além disso, afirmouse que "quanto mais conseguirmos conhecer como a "máquina funciona', melhores serão os resultados envolvidos". As relações com a escola foram estabelecidas por meio do questionamento sobre a rotina, a falta de recursos e a urgência de conciliar necessidades individuais dentro do contexto coletivo:

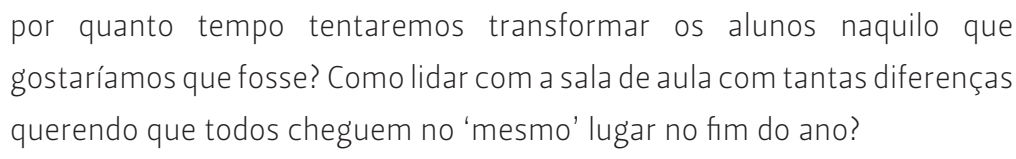

A perspectiva da neuroplasticidade parece animar os educadores:

[...] perceber funções do cérebro de forma mais distribuída, em redes, leva a refletir sobre como motivamos alunos, apesar dos diagnósticos que podem levar a considerar sua capacidade limitada; não devemos trabalhar considerando os limites; os alunos superam dificuldades, psicológica e neurologicamente.

Por outro lado, alguns se sentiram um tanto perplexos, imaginando se estariam capacitados para lidar com tamanho desafio:

Será que nós, educadores, estamos preparados para trabalhar com crianças com distúrbios de aprendizagem? Precisamos conhecer funcionamento do cérebro para entendermos como ocorre a aprendizagem.

Em contraposição, surgiram declarações como: "Sempre acreditei na neuroplasticidade, mesmo quando eu não sabia o que era isso, ou seja, quem acredita busca e faz". É interessante notar que, nessa fala, o que está sendo tomado como neuroplasticidade é, na verdade, potencialidade, de modo que a aluna associa a capacidade de o cérebro modificar-se a partir das experiências 
com as possibilidades que um aluno pode desenvolver quando adequadamente estimulado. Isso também aparece nas seguintes afirmações:
[...] neuroplasticidade mostra o quão inteligente é o cérebro; desistir do aluno é assustador.
[...] indivíduo em relaxamento rende mais, sucesso; não-rótulos; acreditar nas possibilidades SEMPRE; a aprendizagem faz o desenvolvimento, não o contrário [referindo-se a Vigotski].
0 mais importante é saber que o cérebro se desenvolve de acordo com as experiências que ele tem, que precisam ser significativas e prazerosas.

A aula sobre os neuromitos também foi acompanhada com interesse pelas alunas. Nas reflexões, destacou-se a importância de elas serem mais críticas em relação às informações que costumam aceitar sem maiores questionamentos:

\section{[...] uma informação errada ou distorcida nos leva a dar direção errada aos nossos alunos; uma mentira contada várias vezes não pode virar verdade.}

Algumas alunas acharam produtivo o fato de não haver verdades estabelecidas na discussão, o que convoca à autorreflexão. Para outras, no entanto, essa situação parecia frustrar suas expectativas:

\footnotetext{
[...] a neurociência não dá resposta do que é realmente verdadeiro; mais concepções equivocadas do que comprovadas, o que dificulta estabelecer relações com a escola; até agora aprendi o que não fazer.
}

Uma conclusão interessante foi a de que o que é de fato importante é investir na aprendizagem do aluno, ainda que não haja uma confirmação da neurociência em relação a determinada prática:

[... mitos que criamos para satisfazer nossa curiosidade e nosso anseio de respostas, pressão por resultados; desligar-se disso e buscar proporcionar estímulos diversos à aprendizagem, saber o que já está estabelecido direciona o estudo.

A ideia de investir e aceitar a diversidade como única certeza foi discutida, o que concede uma perspectiva otimista sobre o alcance da aula para as alunas:

[...] o educador, ao buscar respostas às suas angustias e fragilidades, encontra muitas vezes ideias equivocadas que de alguma forma o tranquilizam; não há como garantir se existirá educação eficaz aos 
diferentes seres humanos igualmente; o educador precisa trabalhar com suas incertezas diante da diferença na educação.

A aula sobre psicologia histórico-cultural enfatizou alguns conceitos teóricos básicos e teve uma parte lúdica envolvendo exercícios com os temas memória, atenção e percepção, que contaram com participação engajada do grupo. A noção de que não se pode separar o desenvolvimento biológico do social, como propôs Vigotski, também apareceu nos relatos. 0 tópico sobre atenção interessou bastante o grupo, a julgar pelas referências ao mesmo nos relatos. Discutiu-se a importância de considerar o modo como o aluno recebe a informação, pois nem sempre isso ocorre como o professor imagina. Para algumas alunas, faltou uma discussão mais prática:

\section{[...] gostaria de aprofundar para entender melhor meu papel de educadora. Seria a forma de apresentação [de um novo conceito] que não lhe chama a atenção e por isso não memoriza? Seria muita informação ao mesmo tempo? Enfim, discutir esses conceitos na prática contribuiria muito mais.}

0 que parece não ter ficado claro na situação é que isso era o que se esperava que o grupo produzisse, ou seja: mediante as informações e a discussão sobre atenção, o que será que acontece com o aluno? Será que essas hipóteses se verificam ou não? Mais uma vez, a ideia não estava em confirmar práticas por meio de definições conceituais da neurociência, mas propiciar uma apropriação dos conceitos desta em confronto com a experiência educacional de cada um. Em outro exemplo, tal aspecto evidenciase mais claramente:

\footnotetext{
Se a atenção é a capacidade de focar num determinado estímulo, perguntome como posso estimular a atenção de meus alunos se não sei em que estímulo o aluno desatento está focado. Parece-me, pelos exemplos da mesma aula, que isso está intimamente relacionado ao contexto sociocultural em que cada um está inserido. Logo, imagino que se deva conhecer o contexto desse aluno [...] para mediar sua atenção [...]. Devo inseri-lo em outro contexto que não o seu, o contexto da aula. Como? Penso que relacionando seu contexto ao meu, escolar.
}

Observe-se que, nesse relato, a aluna faz uma relação entre o que foi discutido em aula e sua prática escolar, atingindo plenamente o objetivo da escrita reflexiva proposta.

Na aula sobre cognição e emoção como unidade dialética, tal como era de se esperar, houve bastante participação, uma vez que esse tema parece importante e frequentemente presente nas falas dos educadores. É interessante ressaltar que a discussão não se 
limitou às emoções dos alunos, mas também abordou as emoções dos professores:

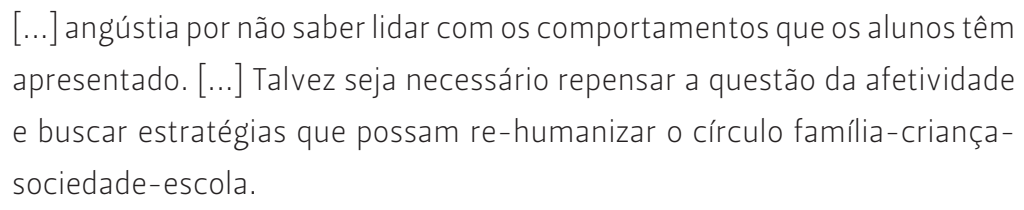

A sugestão feita por Arantes (2002) sobre o trabalho das emoções como conteúdos foi bem acolhida por algumas alunas como uma possibilidade prática de trabalho com o tema. A dialética entre emoção e cognição, discutida a partir de Bechara (2003), foi assunto de uma discussão produtiva, sendo também pontuada nos relatos:

É fundamental que o educador entenda esse funcionamento integrado, a afetividade impulsiona a aprendizagem e a aprendizagem possibilita uma maior afetividade, um 'gostar mais' daquilo que foi aprendido.

Na discussão sobre conceitos-chave da psicologia históricocultural e da neurociência, utilizou-se uma dinâmica a partir de trechos de textos de ambos os campos; as alunas tinham a tarefa de relacionar pares de texto, o que ocasionou uma discussão bastante produtiva, trazendo à baila alguns conceitos recentes da neurociência, como neurônios-espelho, incorporação cerebral de ferramentas, entre outros. Obviamente, o objetivo não era esgotar a compreensão dessas pesquisas - até porque elas ainda se encontram em estado incipiente no próprio campo da neurociência -, mas sim discutir tais dados como evidências da potencialidade e da complexidade humana em seu processo de aprendizagem.

A definição vigotskiana de que a aprendizagem antecede o desenvolvimento, concepção esta que está na base do conceito de zona de desenvolvimento proximal (Vygotsky, 1992), ainda não é claramente compreendida, podendo ser exemplificada por meio de alguns estudos neurocientíficos que mostram justamente essa possibilidade (o desenvolvimento de áreas cerebrais relacionadas à linguagem em pessoas alfabetizadas na idade adulta, como apontaram Carreiras et al., 2009). Tal assertiva coloca em xeque o senso comum que aponta uma suposta imaturidade do aluno para a aprendizagem como justificativa para a não ocorrência desta. De acordo com a fala de uma aluna: 
desenvolvimento de algumas habilidades e [...] a complexidade do que apresentamos aos alunos pode crescer, ampliando o leque deles.

A aula sobre educação inclusiva era uma das mais esperadas. Infelizmente, ela coincidiu com uma reposição de aula em outro dia, de modo que muitos alunos faltaram e, por isso, a pedido daqueles que vieram, não se realizou registro na aula. 0 material, no entanto, foi encaminhado à turma e, na última aula, foram retomados os conceitos principais.

Também houve bastante interesse na aula sobre medicalização, principalmente devido a questões relativas à dislexia e ao TDAH, temas polêmicos e tratados na aula a partir de uma perspectiva crítica sobre a crescente e excessiva medicalização que se tem observado na escola nos dias atuais. Não se trata de um tema fácil, e o enfoque da discussão, criticando as bases sociais dessa produção de fracasso, não foi entendido por todas as alunas, sendo que uma delas sentiu falta de esclarecimento sobre o que cada medicamento acarretaria na aprendizagem; no entanto, a questão a ser respondida era: afinal, por que as crianças estão tomando cada vez mais remédios? Uma explicação possível para isso é que algumas alunas esperavam encontrar na aula uma descrição neurológica de alguns problemas discutidos e a recomendação de qual deveria ser a atitude do professor, ao passo que a ideia era justamente problematizar essas questões com o grupo.

Parte-se aqui do pressuposto de que, na articulação entre neurociência e educação, não cabe ao professor especializar-se em neurotransmissores ou sinapses, sob pena de curvar a vara da discussão para um enfoque biologizante. A questão é justamente olhar para a neurociência com os dois pés fincados na educação, e daí fazer as conjecturas possíveis na linguagem do educador, uma vez que ainda não se esboça uma linguagem comum entre os dois campos a partir da qual seria possível vencer algumas diferenças (Devonshire; Dommet, 2010; Rato; Caldas, 2010), sem que o educador assumisse apenas o papel passivo de receptor de informações de neurocientistas, na expectativa de uma postura prescritiva que sanasse suas dúvidas e acalmasse suas angústias. Para outras alunas, a importância dessa discussão ficou mais evidente: 
Na última aula, realizou-se uma retomada de todo o percurso e abriu-se a possibilidade de discutir dúvidas e questões pendentes. Como ponto positivo, as alunas indicaram a relevância dos temas, bem como a diversidade do material (textos, vídeos etc.). Muitas delas relatam ter gostado de acessar temas que antes desconheciam. Como ponto negativo, ressaltou-se o fato de o grupo ter oscilado, com a alternância de pessoas em aulas diferentes, o que dificultou um pouco a continuidade das discussões. As alunas que avaliaram o curso positivamente apontaram o desejo por uma continuidade, afirmando que o tempo foi pouco para tantos assuntos. Apesar de o site ter funcionado bem, o blog não teve o mesmo efeito, prejudicando a possível interatividade virtual do grupo.

Do ponto de vista da organização do curso, talvez o número de assuntos tratados tenha sido grande, o que se refletiu na impossibilidade de discutir as produções escritas, ainda que os temas fossem debatidos em aula. Solicitar que as alunas escrevessem a cada aula foi bastante produtivo e é algo a se manter em eventuais edições posteriores do curso. Como contribuição específica ao novo campo de articulação entre a neurociência e a educação, ressalta-se a importância de estratégias em que os professores tenham um papel participativo e reflexivo, tal como apontam Dommett e colaboradores (2009), o que certamente possibilitará um futuro promissor a essas discussões.

\section{REFERÊNCIAS}

ARANTES, Valéria Amorim. Afetividade e cognição: rompendo a dicotomia na educação. 2002. Disponível em: <http:// www.hottopos.com/videtur23/valeria.htm>. Acesso em: 1 set 2010 .

BECHARA, Antoine. O papel positivo da emoção na cognição. In: ARANTES, Valéria Amorim (Org.). Afetividade na escola: alternativas teóricas e práticas. São Paulo: Summus, 2003. p. 191-213.

BRUER, John T. Education and the brain: a bridge too far. Educational Researcher, v. 2, p. 4-16, 1997.

CARREIRAS, Manuel et al. An anatomical signature for literacy. Nature, v. 461, n. 15, p. 983-988, out. 2009. 
DEVONSHIRE, Ian M.; DOMMET, Eleanor J. Neuroscience: viable applications on education? The Neuroscientist, v. 16, n. 4, p. 349-356, 2010.

DOMMETT, Eleanor J. et al. From scientific theory to classroom practice. The Neuroscientist, v. 20, n. 10, p. 1-7, 2009.

GEAKE, John. Neuromythologies in education. Educational Research, v. 50, n. 2, p. 123-133, 2008.

GOSWAMI, Usha. Neuroscience and education: from research to practice? Nature Reviews Neuroscience/AOP, 2006.

Disponível em: <www.nature.com/reviews/neuro>. Acesso em: 26 dez. 2009.

Principles of learning, implications for teaching: a cognitive neuroscience perspective. Journal of Philosophy of Education, v. 42, n. 3-4, p. 381-399, 2008.

OECD - Organisation for Economic Co-operation and Development. Understanding the brain: the birth of a learning science. Paris: Centre for Educational Research and Innovation, OECD Publishing, 2007.

ORTEGA, Francisco; VIDAL, Fernando. Mapeamento do sujeito cerebral na cultura contemporânea. RECIIS: Revista Eletrônica de Comunicação, Informação e Inovação em Saúde, Rio de Janeiro, v. 1, n. 2, p. 257-261, jul.-dez. 2007.

RATO, Joana Rodrigues; CALDAS, Alexandre Castro.

Neurociências e educação: realidade ou ficção? In: SIMPÓSIO NACIONAL DE INVESTIGAÇÃO EM PSICOLOGIA, 7., 2010, Braga. Actas... Braga: Universidade do Minho, 2010. p. 626-644.

VIGOSTKY, Lev S. Aprendizagem e desenvolvimento intelectual na idade escolar. In: VIGOSTKY, Lev S.; LURIA, Alexander; LEONTIEV, Alexis. Linguagem, desenvolvimento e aprendizagem. 4. ed. São Paulo: Ícone, 1992.

WILLINGHAM, Daniel T. Three problems in the marriage of neuroscience and education. Cortex, v. 45, n. 4, p. 544-545, 2009.

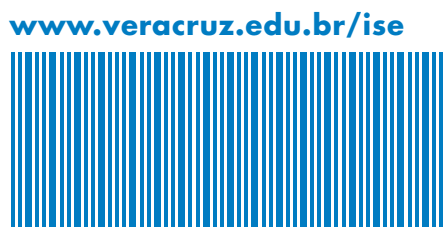

